\title{
E. Boltshauser and J. Schmahmann (eds): a Top Companion for Paediatric Ataxiology
}

\author{
Cerebellar Disorders in Children, Mac Keith Press, London (UK), 2012, 435 Pages, 27 \\ Colour Plates
}

Mario Manto

Published online: 17 February 2012

(C) Springer Science+Business Media, LLC 2012

The neuroscience of the cerebellum is in a fantastic period. With a growing recognition that the cerebellar circuits are involved in numerous and complex motor and non-motor operations, the advent of sensitive techniques both at the experimental and clinical level and the recent developments of molecular genetics, cerebellar disorders cannot be neglected and taken out away from the global neurological symptomatology anymore.

Although several books have been published on cerebellar disorders these last decades, a comprehensive and up-to-date book dedicated to cerebellar disorders in children was clearly missing. The book edited by two renowned authors, Eugen Boltshauser (University Children's Hospital, Zurich, Switzerland) and Jeremy Schmahmann (Massachusets General Hospital, Boston, USA), is filling this gap in an outstanding manner. With their practical expertise, the editors have masterly organised the book into nine parts: cerebellar development, cerebellar anatomy and functions, imaging, malformations, genetic and metabolic disorders, cerebellar disruptions in prenatal period and in the preterm infant, vascular disorders/tumours/paraneoplastic cerebellar syndromes, acute ataxias and extrinsic insults. In addition to the 42 chapters written by a group of 36 experts, very useful checklists made of 29 tables are also provided at the end of the book. The authors introduce very well each disorder discussed, so that the reader is not lost during the reading. The dazzling guidance of the editors can be sensed throughout the chapters, giving a strong support to the concept of an 'edited book' in the rising discipline of paediatric ataxiology.

The clinically relevant embryology is particularly well discussed throughout the book with a special effort in trying to keep the writing homogeneous and enjoyable for the reader, despite the difficulty of the topic. All imaging modalities are discussed and advances in genetics are very well covered. Pictures and drawings complement the text appropriately and the selection of brain MRI images will be of great interest for daily clinical neurological practice, not only in the field of paediatrics, but also for neurologists taking care of adults. The authors have put efforts to help the clinician circulating in the labyrinth of cerebellar disorders, which have often a complex presentation in children.

With its exhaustive coverage, the clarity of its presentation and the careful selection of references, this book cancertainly - be recommended to any clinician or neuroscientist dealing with cerebellar disorders in children. It fully deserves a foreground position in a medical library. The ambitious intent to create a multi-authors, sound and clinically oriented work on cerebellar disorders affecting children is achieved. 